\title{
ORIGINAL ARTICLE \\ Fructose content and composition of commercial HFCS-sweetened carbonated beverages
}

\author{
JS White ${ }^{1}$, LJ Hobbs ${ }^{2}$ and S Fernandez ${ }^{3}$
}

\begin{abstract}
OBJECTIVE: The obesigenic and related health effects of caloric sweeteners are subjects of much current research. Consumers can properly adjust their diets to conform to nutritional recommendations only if the sugars composition of foods and beverages is accurately measured and reported, a matter of recent concern. We tested the hypothesis that high-fructose corn syrup (HFCS) used in commercial carbonated beverages conforms to commonly assumed fructose percentages and industry technical specifications, and fulfills beverage product label regulations and Food Chemicals Codex-stipulated standards.

DESIGN: A high-pressure liquid chromatography method was developed and verified for analysis of sugars in carbonated beverages sweetened with HFCS-55. The method was used to measure percent fructose in three carbonated beverage categories. Method verification was demonstrated by acceptable linearity $\left(R^{2}>0.99\right)$, accuracy $(94-104 \%$ recovery) and precision (RSD $<2 \%)$. RESULT: Fructose comprised $55.58 \%$ of total sugars (95\% confidence interval $55.51-55.65 \%$ ), based on 160 total measurements by 2 independent laboratories of 80 randomly selected carbonated beverages sweetened with HFCS- 55 . The difference in fructose measurements between laboratories was significant but small $(0.1 \%)$, and lacked relevance. Differences in fructose by product category or by product age were not statistically significant. Total sugars content of carbonated beverages showed close agreement within product categories (95\% confidence interval $=0.01-0.54 \%$ ).

CONCLUSIONS: Using verified analytical methodology for HFCS-sweetened carbonated beverages, this study confirmed the hypothesis that fructose as a percentage of total sugars is in close agreement with published specifications in industry technical data sheets, published literature values and governmental standards and requirements. Furthermore, total sugars content of commercial beverages is consistent with common industry practices for canned and bottled products and met the US Federal requirements for nutritional labeling and nutrient claims. Prior concerns about composition were likely owing to use of improper and unverified methodology.
\end{abstract}

International Journal of Obesity (2015) 39, 176-182; doi:10.1038/ijo.2014.73

Keywords: dietary carbohydrates; fructose; high-fructose corn syrup; nutritive sweeteners; sweetening agents; carbonated beverages

\section{INTRODUCTION}

High-fructose corn syrup (HFCS) is one of the most scrutinized food ingredients of the past half-century. HFCS is viewed as a trusted, dependable and safe formulation component by the food and beverage industry, however, its use has declined significantly over the past decade. This decline is owing both to shifting lifestyle trends-more consumption of water and reduced-calorie foods and beverages-and to attention focused on claims that HFCS may be a unique obesity and related health risk, ${ }^{1}$ despite strong scientific evidence that its metabolism is no different than sucrose. $^{2,3}$

Because of the interest in understanding the metabolic and nutritional effects of caloric sweeteners-especially HFCS - the accurate measurement and reporting of individual sugars in complex food and beverage matrices is essential. The industry credibility that is fundamental to consumer trust was recently called into question by a suggestion that the level of fructose in carbonated beverages is greater than that claimed by manufacturers. ${ }^{4}$ The International Society of Beverage Technologists (ISBT) has been involved in development of industry standards and best practices regarding carbohydrates for over 50 years.
ISBT saw the need to develop and verify a method to determine fructose levels in HFCS-sweetened carbonated beverages that would account for the presence of carbonation, lower sweetener solids and additional ingredients present in the carbonated beverage matrix.

\section{Brief history of HFCS}

At several times in the past 50 years, disruptions in sucrose production led to critical shortages and corresponding price spikes, causing economic and production hardship in food and beverage manufacturing. As a partial remedy, HFCS was developed in the 1960s as a liquid sweetener alternative to sucrose. After its introduction to the food and beverage industry in the 1970s, HFCS usage underwent rapid growth during the 1980s, especially in beverage applications. Its comparable sweetness (HFCS-55) allowed ready substitution in product formulas, its liquid form offered handling advantages during production and its monosaccharide composition offered stability over sucrose in acidic beverages. By the 1990s, HFCS was well established as a stable, domestic sweetenerin the United States, where its use is second only to sucrose. ${ }^{5}$ Although it accounts internationally for

${ }^{1}$ White Technical Research, Argenta, IL, USA; ${ }^{2}$ International Society of Beverage Technologists, Dallas, TX, USA and ${ }^{3}$ Department of Biomedical Informatics, Center for Biostatistics, The Ohio State University, Columbus, OH, USA. Correspondence: Dr JS White, White Technical Research, 8895 Hickory Hills Drive, Argenta, IL, USA. 
only $8 \%$ of combined sweetener use (with sucrose), concern has been raised that it poses a global health threat. ${ }^{6}$

There is often confusion among scientists and the lay public alike about starch-derived corn syrup products: regular corn syrup is comprised entirely of glucose and glucose oligomers; HFCS is produced by an enzymatic process that leads to partial isomerization of glucose resulting in fructose formation. HFCS is principally sold in two forms-HFCS-42 and HFCS-55characterized by the amount of fructose each contains, either $42 \%$ or $55 \%$, respectively; the balance is primarily glucose (dextrose) and a small percent of short-chain glucose oligomers (predominantly maltose, maltotriose and maltotetraose). Since the introduction of HFCS, its sugars composition has been widely understood to approximate that of sucrose (half glucose and half fructose), based on information supplied in manufacturer technical specifications brochures, ${ }^{7,8}$ descriptions in the scientific literature $\mathrm{r}^{5,9-12}$ and specific product requirements codified in government regulatory documents. ${ }^{13,14}$

After existing in relative obscurity for $>3$ decades, HFCS came under close scrutiny in 2004, singled out among other commonly used nutritive/caloric sweeteners (including sucrose, honey and fruit juice concentrates) as a potentially unique contributor to obesity in the United States. ${ }^{1}$ Recent clinical studies and reviews have provided strong evidence that HFCS-55 and sucrose are nutritionally equivalent ${ }^{3,15-19}$ —also recognized by authoritative bodies $^{20,21}$ - however, confusion still remains.

Nutritional recommendations about the amount of total sugars appropriate for a healthy diet have been provided for many years but lack general agreement. For example, the Institute of Medicine recommends that total sugars comprise $\leqslant 25 \%$ of daily energy intake $^{22}$ and the American Heart Association more conservatively recommends that women and men take in $\leqslant 100$ and $150 \mathrm{kcal}$ per day from added sugars, respectively (close to $5 \%$ of the diet), ${ }^{23}$ whereas the World Health Organization suggests free sugars should comprise $<10 \%$ of calories in the diet. ${ }^{24}$ To be able to follow even diverse nutritional recommendations such as these, the public must have confidence not only that food and beverage labels contain accurate composition information, but that the ingredients they contain adhere to advertised and accepted composition standards.

The Institute of Medicine Food Chemicals Codex stipulates the following identity standards for the sugars composition of HFCS, ${ }^{13}$ which are incorporated by reference into the US Food and Drug Administration Code of Federal Regulations: ${ }^{14}$

$42 \%$ HFCS: not $<97.0 \%$ total saccharides, expressed as a percentage of solids, of which not $<42.0 \%$ consists of fructose, not $<92.0 \%$ consists of monosaccharides and not $>8.0 \%$ consists of other saccharides. $55 \%$ HFCS: not $<95.0 \%$ total saccharides, expressed as a percentage of solids, of which not $<55.0 \%$ consists of fructose, not $<95.0 \%$ consists of monosaccharides and not $>5.0 \%$ consists of other saccharides.

It is important to note that the standards stipulate minimum fructose percentages to be met. In practice, HFCS manufacturers target fructose percentages slightly above the minimum standards in order to remain in compliance and avoid product rejections by customers. But there is also a strong economic incentive not to exceed the minimum standard by more than is required to routinely meet the specification: fructose is costly to produce, as it requires the enzymatic process outlined above. In addition, food and beverage industry customers demand sweetener ingredients of known and consistent composition in order to avoid unnecessary formulation adjustments.

\section{Brief history of HFCS analytical methods}

Technology for sugars separation and measurement progressed concurrently with the commercial development of HFCS. Experimentation with thin-layer chromatographic separations by Huber et al. ${ }^{25}$ at the AE Staley Manufacturing Company led to the application of high-pressure liquid chromatography to corn-derived sweeteners in 1973 by Brobst, Scobell and Steele; ${ }^{26}$ subsequent papers refined this technology. ${ }^{27-29}$ An early collaborative study by Engel and Olinger $^{30}$ established cation-exchange resin column chromatographic separation coupled with quantification by differential refractometry as the standard method for rapid corn syrup analysis. This was the basis for development of two methods: AOAC 979.23 saccharides (major) in corn syrup 31 and CIRF method E-61, saccharides (liquid chromatography) ${ }^{32}$ from the Corn Industries Research Foundation, now method Sacch.03 (Revision 4/1/2009) of the Corn Refiners Association.

During this same period, work by Wartman et al. $^{33-35}$ at the Augustana Research Foundation established the refractive index (RI)-dry substance relationships of starch-derived syrups, essential to quantifying and standardizing syrup carbohydrate profiles.

In the early 1980s, the Sweetener Technical Committee of the Society of Soft Drink Technologists (now called ISBT) formed a subcommittee comprised of industry chemists to codify the appropriate standards and methodology for testing high-fructose syrups. The subcommittee built upon updated RI data provided by the Augustana Research Foundation, CIRF method E-61 and a statistical analysis of several thousand shipments of HFCS to establish method 3.0-Saccharides in HFCS, ${ }^{36}$ published in 1985 and used throughout the world in company specifications and government regulations.

Because AOAC 979.23, CIRF E-61 and ISBT method 3.0 specifically address the measurement of saccharides in a corn syrup solution, a validated procedure was needed to measure sugars composition in a more complex beverage matrix containing non-carbohydrate ingredients. Possible interferences could come from carbonation, colorants, flavors, acidulents and other components in the beverage formulation. ISBT modified the procedure as method 3.2-Saccharides in Soft Drinks in 2013 to include conditions for measurement of HFCS sugars in commercial (finished) beverages. ${ }^{37}$

\section{HYPOTHESIS}

Through use of appropriate and verified methodology, we tested the hypothesis that HFCS used in commercial carbonated beverages conforms to commonly assumed fructose percentages and industry technical specifications, and fulfills beverage product label regulations and Institute of Medicine Food Chemicals Codexstipulated standards.

\section{MATERIALS AND METHODS}

\section{High-pressure liquid chromatography}

Two independent commercial testing laboratories, Covance Laboratories Inc. (Madison, WI, USA) and Silliker Inc. (Crete, IL, USA), were employed to separate and quantify component sugars and verify the ISBT method 3.2-Saccharides in Soft Drinks. ${ }^{37}$ Method 3.2 is an extension of the ISBT Method 3.0-Saccharides in HFCS, ${ }^{36}$ a verified method for separating and quantifying HFCS sugars in aqueous solution. Both high-pressure liquid chromatography methods use a Bio-Rad Aminex HPX-87C column (Bio-Rad Laboratories, Hercules, CA, USA) coupled to an RI detector. Method 3.2 was adapted for measurement of HFCS sugars in carbonated beverage matrices.

\section{Method verification protocol}

Sugars reference standards. The primary sugars in HFCS are fructose, glucose, maltose, maltotriose and maltotetraose. Authentic reference standards of these sugars were prepared from Sigma USP or Bio-Ultra Grade purity reagents (Sigma-Aldrich Co. LLC, St Louis, MO, USA). Standards were corrected for moisture using the Karl Fischer Method. ${ }^{38}$

Linearity. Aqueous samples of authentic sugars reference standards were prepared over the concentration range expected in carbonated beverages. 
Peak area responses for sugars in each sample were determined by highpressure liquid chromatography with RI detection using the ISBT Method 3.2-Saccharides in Soft Drinks and plotted against actual concentrations. The criterion for acceptable linearity was a coefficient of determination $\left(R^{2}\right)$ $>0.99$ calculated from a linear regression model.

Accuracy. Known amounts of authentic reference sugars standards were spiked into an unsweetened cola beverage matrix at 80,100 and $120 \%$ of the expected concentration in finished products. Ten replicate determinations were made at each spike level (total of 30 injections) by both labs to assess accuracy. The percentage of spike recovery, mean and relative standard deviation (RSD) were calculated for each sugar component. Accuracy was reported as percent recovery of the actual spiked amount together with confidence intervals. The criterion for acceptable accuracy was percent recovery in the range of $94-104 \%{ }^{39}$

Precision. Ten replicate determinations covering the expected concentration in carbonated beverages (100\% spike from above) were used to assess intermediate precision (within-lab precision). The average \% recovery between the two labs, RSD and the confidence interval are reported. These values do not represent the reproducibility, as only two labs were involved, but give an idea of the overall precision and its bounds. The criterion for acceptable precision within a laboratory was $\mathrm{RSD}<2 \%$ among the 10 replicates. ${ }^{39}$

\section{HFCS-sweetened carbonated beverages}

A total of 80 samples of carbonated beverages sweetened with HFCS-55 and manufactured by three bottling companies (The Coca-Cola Company (Atlanta, GA, USA), PepsiCo (Purchase, NY, USA) and Dr Pepper Snapple Group (Plano, TX, USA)) were randomly collected from retail store shelves around the country in three flavor categories: 30 cola samples (10 each of Coca-Cola, Pepsi and RC Cola); 30 lemon lime samples (10 each of Sprite, Sierra Mist and 7-Up); and 20 pepper-type samples (10 each of Mr. Pibb and Dr Pepper). Covance and Silliker laboratories were provided with blinded samples for independent analysis using the ISBT method 3.2-Saccharides in Soft Drinks. The identity of samples was unknown to the authors and the laboratories until analysis was completed. Samples represented unique production batches ( 80 samples from 78 lots), and a range of US geographic regions and product ages (proxy for variable shelf life and transportation/ storage conditions; age range: 9-331 days). HFCS-55 from all domestic suppliers was represented within the 80 samples.

Samples were decarbonated by sonication before analysis. Each of the 80 samples was injected one time for carbohydrate composition. Dry-solid levels were determined by Rl. Analytical results from each laboratory were sent to the intermediary for collation. Raw data for flavor category, geographic region and production date were unblinded for author SF only, for statistical analysis; the manufacturer of individual beverage samples remained blinded.
Statistical analysis

Method verification. Percent differences between verification data obtained from each lab and authentic standard for each sugar type were calculated. Descriptive statistics (means and confidence intervals) were computed. A one-sample $t$-test was used to test the null hypothesis that the average difference in percent fructose is zero vs the alternative hypothesis that it is not zero (that is, two-tailed test: $H_{0}: \mu$ diff $=0$ vs $H_{a}$ : $\mu_{\text {diff }} \neq 0$ ).

HFCS-sweetened carbonated beverages. Percent of total sugars as fructose, glucose and DP2+ (sum of maltose, maltotriose, maltotetraose and higher saccharides) in carbonated beverage samples were statistically analyzed for differences between labs, between product categories and for the effect of product age. After assessing the distributions of sugars percentages for/or lack of normality (Shapiro-Wilk test) ${ }^{40}$ mixed models were used to study the effects of labs, product categories and product age and the interactions lab-by-category and product age-by-category on fructose, glucose and DP2+ (SAS: proc mixed, random intercept, subject $=$ sample ID and compound symmetry covariance structure). These mixed effects models included a random source effect to take into account the correlation between samples taken from the same source. Product age was also treated as a random effect. Lab and product category were included as fixed effects. Pairwise comparisons between product types were adjusted using the Bonferroni method to control for type I error rate. ${ }^{41}$ SAS version 9.2 (SAS Institute Inc., Cary, NC, USA) was used to perform these analyses.

\section{RESULTS}

Verification of ISBT Method 3.2-Saccharides in Soft Drinks

The utility of the method in chromatographically resolving the predominant sugars in HFCS was tested using an aqueous mixture of authentic sugar standards: fructose, glucose, maltose, maltotriose and maltotetraose. Clean separation and baseline resolution was achieved for the primary sugar of interest-fructose-and acceptable resolution for the remaining sugar components. More importantly, the method capably separated sugars in commercial HFCS-sweetened carbonated beverage (Figure 1). Note that the only sugars of consequence in the beverage were those commonly assumed to comprise HFCS.

\section{Linearity}

Linearity in the ISBT Method 3.2-Saccharides in Soft Drinks was assessed over the range (80, 100 and $120 \%$ ) of expected sugars concentrations using authentic sugars standards in aqueous solution. Peak area response vs known concentration was plotted

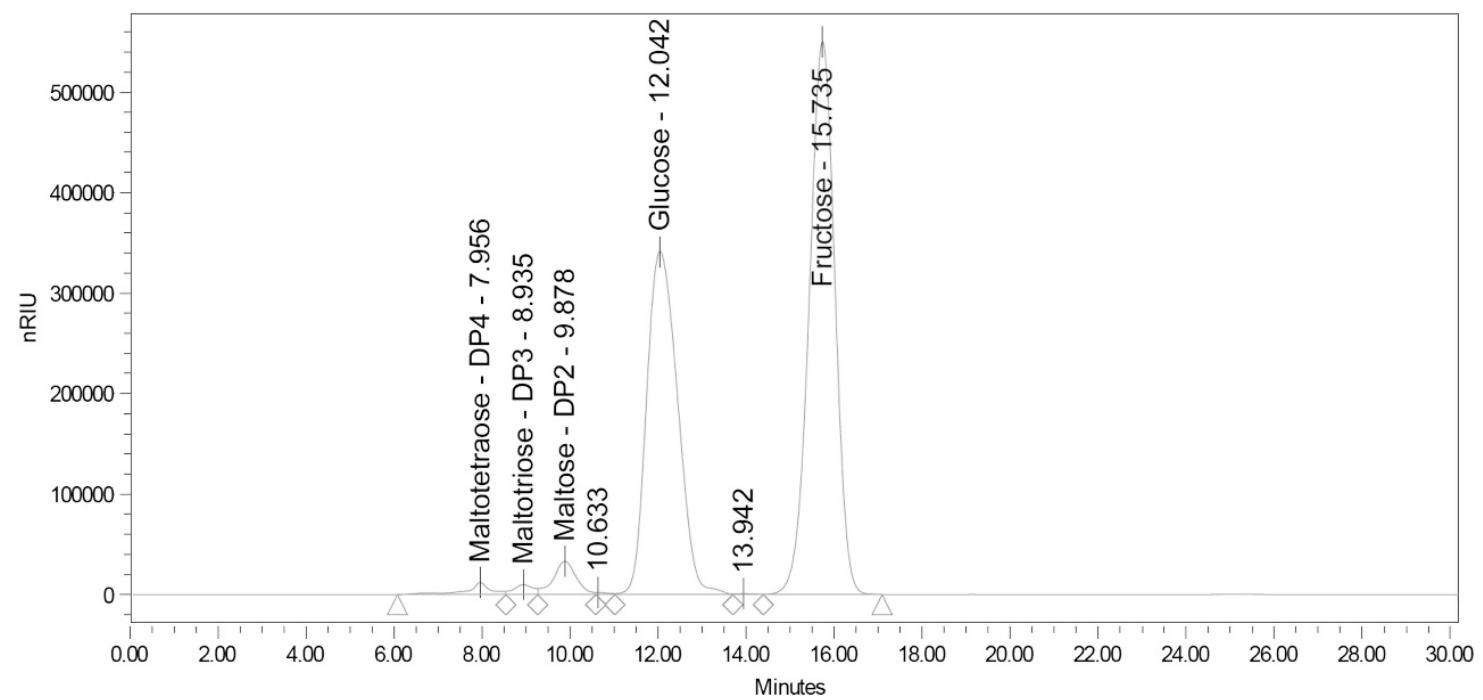

Figure 1. Separation of sugars in commercial HFCS-sweetened beverage. 
for each HFCS sugar component, linear regression lines were drawn and $R^{2}$ values were calculated. Composite (pooled) and individual lab $R^{2}$ values for three HFCS sugars fractions are reported in Table 1.

\section{Accuracy}

Known amounts of authentic reference sugars were spiked into a beverage matrix at 80,100 and $120 \%$ of the expected concentration in HFCS-sweetened carbonated beverages. The percentage of spiked sugar recovery, mean and RSD were calculated for three sugars fractions at each expected concentration level (10 injections per concentration level per lab). Mean percent recovery and 95\% confidence intervals are reported in Table 1 for composite data and individually for labs 1 and 2 .

\section{Precision}

Known amounts of authentic reference sugars were spiked into a beverage matrix at $100 \%$ of the expected concentration in HFCSsweetened carbonated beverages. Precision (repeatability) was assessed from RSD and confidence interval (10 injections per lab). The data are reported in Table 1 for composite data and individually for labs 1 and 2 .

\section{Method verification}

Descriptive verification statistics for percent fructose, glucose and DP2+ are shown in Table 1. Labs 1 and 2 reported mean fructose composition differences vs authentic standards of $0.075 \%$ and $0.093 \%$, and $95 \%$ confidence interval ranges of $0.272 \%$ and $0.133 \%$, respectively. Pooling data from both labs resulted in an overall mean fructose composition difference of 0.010 and $95 \%$ confidence interval width of $0.153 \%$. The $t$-test for the null hypothesis $\left(\mathrm{H}_{0}\right)$ of fructose mean difference $=0$ vs the alternative $\left(\mathrm{H}_{\mathrm{a}}\right)$ of fructose mean difference $\neq 0$ was highly non-significant $(P$-value: 0.804). Therefore, the conclusion from the statistical test is that there is no evidence to reject $\mathrm{H}_{0}$. This strongly verifies lab measurements by demonstrating that reported sugars composition values do not deviate from their authentic standard.
Composition of sugars in HFCS-sweetened carbonated beverages Descriptive statistics, both composite and individual lab, are provided in Table 2 for three sugars fractions in HFCS-sweetened carbonated beverages.

Dry solids measurements were consistent within product categories, with $95 \%$ confidence interval width of $0.01-0.54 \%$.

\section{Statistical modeling of percent fructose}

The two interaction terms lab-by-category and product age-bycategory were not statistically significant for any of the models using each of the three outcome variables (percent fructose, percent glucose or percent DP2+). Therefore, these interaction terms were excluded from the final models, leaving only the three main factors in the percent fructose model for further consideration. It should be noted that model-estimated means in the final model are very close to actual raw means.

The two primary fixed factors, lab and product, had $P$-values of 0.0018 and 0.0662 , respectively. Although the difference in percent fructose between labs was significant, the difference was not relevant in magnitude (the estimated mean difference was $0.1 \%)$. Mathematically, the significant $P$-value originated from the small s.d. and relatively large sample size. Given the high precision and accuracy of the measurements, the s.d. was small and therefore a slight difference in means would be detected as significant.

The pairwise comparison of each product category vs the average of the other two gave adjusted $P$-values of $0.15,0.066$ and $>0.99$, respectively, for cola, lemon lime and pepper. None of the comparisons showed a significant $P$-value, therefore the null hypothesis of no difference between each of the products percent fructose and the average of the other two could not be rejected.

Product age was included in the three mixed effect models as a random effect. It was highly non-significant in all models. For percent of fructose, the $P$-value was 0.8370 , indicating that the variability in percent fructose is independent of, and not affected by, product age. It was similarly non-significant for percent of glucose or percent of DP2+ (P-values: 0.2789 and 0.1296 , respectively). The zero coefficients for product age in the three models and the zero s.e. indicate this factor can be removed from the models, as it had no effect on any of the three sugars fractions.

Table 1. Method verification measures: linearity, accuracy, precision and verification HFCS sugars fraction

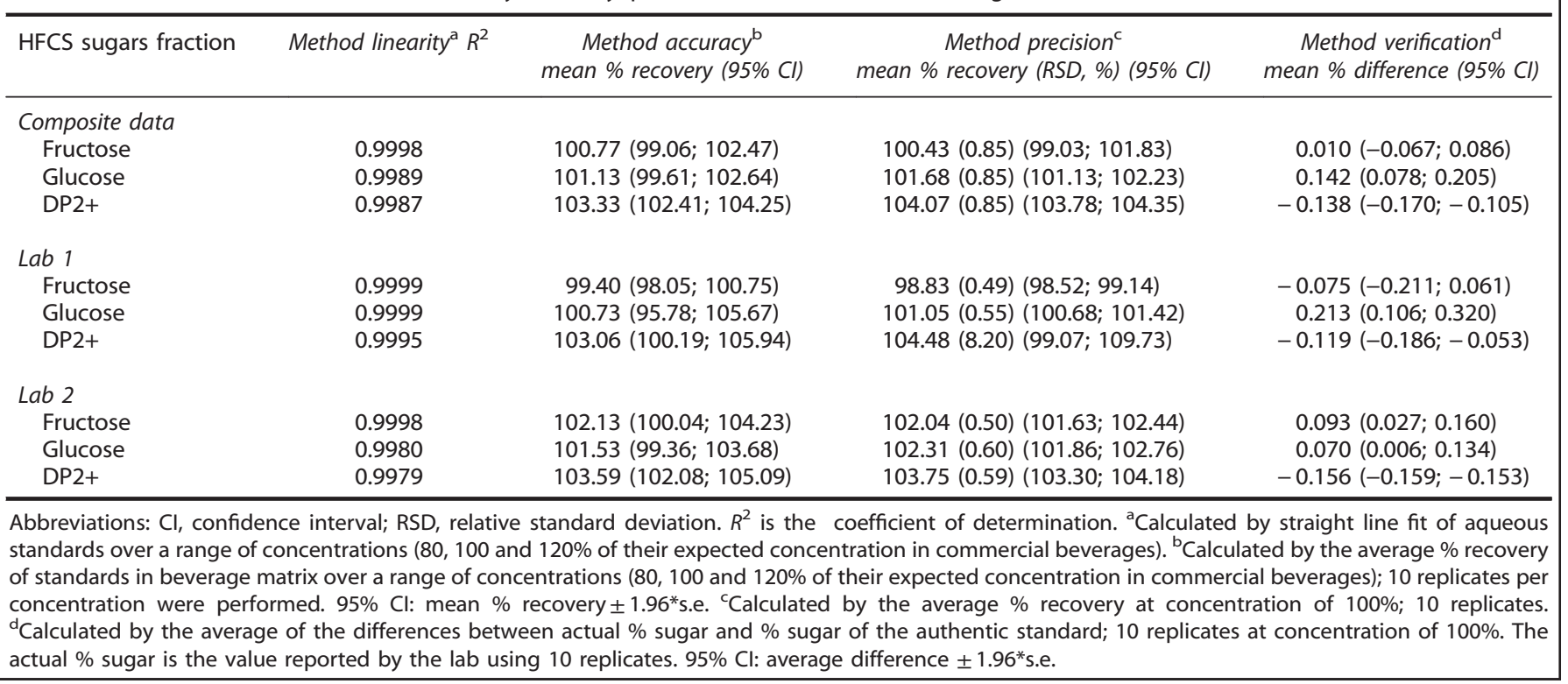


Table 2. Mean percent composition and $95 \%$ confidence interval for three sugars fractions in 80 commercial carbonated beverages sweetened with HFCS-55

\begin{tabular}{lcc}
\hline HFCS sugars fraction & Mean \% composition & 95\% Confidence interval \\
\hline $\begin{array}{l}\text { Composite data } \\
\text { Fructose }\end{array}$ & 55.58 & $(55.51 ; 55.65)$ \\
$\quad$ Glucose & 39.71 & $(39.61 ; 39.81)$ \\
$\quad$ DP2+ & 4.70 & $(4.59 ; 4.81)$ \\
& & \\
Lab 1 & & \\
$\quad$ Fructose & 55.63 & $(55.54 ; 55.72)$ \\
$\quad$ Glucose & 40.19 & $(40.09 ; 40.28)$ \\
$\quad$ DP2+ & 4.17 & $(4.09 ; 4.26)$ \\
& & \\
Lab 2 & & $(55.41 ; 55.64)$ \\
$\quad$ Fructose & 55.53 & $(39.15 ; 39.34)$ \\
$\quad$ Glucose & 39.24 & $(5.12 ; 5.34)$ \\
$\quad$ DP2+ & 5.23 & \\
\hline Abbreviation: HFCS, high-fructose corn syrup. & \\
\hline
\end{tabular}

\section{DISCUSSION}

In this paper, we provide evidence that the concern about HFCS manufacturers and soft drink bottlers possibly misleading the public by exceeding commonly assumed fructose percentages in HFCS-55 is unfounded. Two independent laboratories used verified separation and detection methodology designed specifically for the unique conditions of an HFCS-sweetened carbonated beverage matrix. Each lab analyzed 80 samples randomly pulled from retail store shelves in a variety of flavor categories, manufacturing locations and product ages, manufactured by the three largest US carbonated beverage companies and using HFCS-55 from all US manufacturers.

\section{Method verification}

The ISBT method 3.2-Saccharides in Soft Drinks met all verification criteria for linearity, accuracy and precision defined in the protocol. On the basis of method verification data, both laboratories were qualified to run HFCS-sweetened carbonated beverages for the study.

Fructose percentage in commercial HFCS-sweetened carbonated beverages

Although the slight difference in fructose between labs was statistically significant-a consequence of high-precision/highaccuracy measurements and small s.d./large sample size-its relevance was low, given the small magnitude $(0.1 \%)$. Differences in fructose by product category or by product age were not significant.

The central question asked in this paper-what is the fructose percentage in commercial HFCS-sweetened beverages?-is answered in Table 2. Our analysis showed the fructose percentage in pooled data to be $55.58 \%$ ( $95 \%$ confidence interval $55.51-$ $55.65 \%$ ) of total sugars, based on 160 total measurements by 2 independent laboratories of 80 randomly selected carbonated beverages sweetened with HFCS-55. Although our fructose percentage is at odds with that reported by Ventura et al. ${ }^{4}$ - mean fructose level 59\%, range $47-65 \%$-it is in close agreement with the $55 \%$ value published in industry technical specifications sheets ${ }^{8}$ and the scientific literature, ${ }^{5,9-12}$ and the $\geqslant 55 \%$ value stipulated in governmental regulatory standards and requirements. ${ }^{13,14}$ As noted earlier, HFCS-55 manufacturers must meet the regulatory minimum standard of $55 \%$ fructose, so must overshoot the minimum slightly to prevent product rejections from food and beverage customer quality control labs.
It appears the discrepancy between results of Ventura et al. ${ }^{4}$ and ours is a methodological one. They applied the AOAC method 977.20-Separation of Sugars in Honey to their analysis of carbonated beverages. As pointed out by Hobbs and Krueger, ${ }^{42,43}$ it is important to use a method verified for the specific sugars composition and matrix being studied. Although honey and HFCS both contain fructose, glucose and higher saccharides, honey also contains appreciable sucrose and nonsucrose disaccharides. ${ }^{44,45}$ Honey method 977.20 is typically standardized against fructose, glucose and sucrose only, so will miss other sugars present and incorrectly inflate the percent composition of fructose. As was the case in Ventura et al., ${ }^{4}$ if only fructose and glucose-instead of total sugars-were used to calculate percent fructose, the potential for error is compounded. A strength of our study is that underlying the ISBT method 3.0 was verified for separating and quantifying the specific sugars in HFCS, and the adapted ISBT method 3.2 was verified in this study for use in carbonated beverages. ${ }^{36,37}$ Fructose, glucose and higher saccharides were all used in the calculation of percent fructose.

Total sugars content of commercial HFCS-sweetened beverages In products like sugar-sweetened carbonated beverages, the sweetener provides nearly all the dry solids. It is common practice in the beverage industry to use dry solids as a proxy for total sugars content. Total sugars content of commercial HFCSsweetened beverages, as estimated by dry solids measurements, showed close agreement within product categories (95\% confidence interval=0.01-0.54\%). Importantly, the total sugars contents conformed to typical industry formulae for cola, lemon lime and pepper-type products, and meet US Federal requirements for nutrition labeling and nutrient claims.

Sugars composition of commercial HFCS-sweetened beverages As summarized in Table 2, the principal sugars in HFCS-55 are fructose, glucose and DP2+ (also called higher sugars or higher saccharides). These sugars and their percent composition have been a consistent and invariable characteristic of HFCS-55 since its introduction $>40$ years ago.

Ventura et al. ${ }^{4}$ found no inconsistencies in HFCS-sweetened beverages, but did report discrepancies between types of sugars claimed on product labels and those detected in sucrosesweetened beverages. However, their sucrose concern was almost certainly a failure to consider acid-catalyzed sucrose inversion to free fructose and glucose, a well-characterized phenomenon known to occur in the low-pH environment of most carbonated beverages (and a host of other acidic foods and beverages). Thus, concern about types of sugars in HFCS- and sucrose-sweetened beverages appears to be based on incomplete understanding of sugars chemistry in carbonated beverages.

Caution must also be exercised in interpreting the results of gas chromatography-mass spectrometry analyses of HFCS, sucrose and other sugars where acid hydrolysis is used. Although its stated purpose is to hydrolyze di- and oligosaccharides to constituent monosaccharides before analysis, acidification can readily degrade fragile sugars and create a host of artifacts not present in the original sample. In addition, the elevated column and pre-column temperatures inherent in gas chromatography-mass spectrometry separations accelerate sugar degradation reactions. These factors are likely explanations for differences in HFCS composition reported by Wahjudi et al., ${ }^{46}$ based on gas chromatographymass spectrometry comparisons with and without acid pretreatment.

\section{CONCLUSIONS}

Concern was recently raised that HFCS manufacturers and soft drink bottlers may be misleading the public by exceeding 
commonly assumed fructose percentages in HFCS- $55,{ }^{4}$ and the excess vis-à-vis sucrose was suggested as a primary driver of unfavorable impacts on metabolic health. ${ }^{6,47-50}$ Using verified analytical methodology, this study showed unequivocally that fructose as a percentage of total sugars in carbonated beverages sweetened with HFCS-55 is reasonably close to the $55 \%$ minimum stipulated by regulatory standards, given the practicalities of large-scale sweetener and beverage production. This study further demonstrated that the total sugar content in beverages randomly sampled throughout the United States accurately reflects not only what is communicated by beverage manufacturers, but also what is stated on the nutrition facts panel of product labels.

There is considerable evidence from randomized controlled studies demonstrating that the body similarly metabolizes

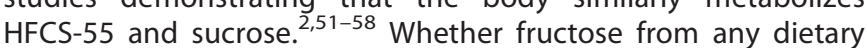
source is linked to the rise in contemporary diseases of metabolic origin remains a contentious issue. Those who claim a link ${ }^{59,60}$ rely heavily on epidemiologic evidence, and data gathered in animals or humans using protocols comparing isolated sugars at extreme doses, which bear little resemblance to the way humans use fructose. ${ }^{2,61}$ Recent papers by Sievenpiper et al. ${ }^{51,52,54,62}$ and Johnston et al. ${ }^{63}$ suggest that reports of untoward fructose effects may be energy related rather than monosaccharide specific.

Our hypothesis was confirmed that HFCS used in commercial carbonated beverages conforms to commonly assumed fructose percentages and industry technical specifications, and fulfills beverage product label regulations and Food Chemicals Codexstipulated standards.

\section{CONFLICT OF INTEREST}

This study was solely supported by ISBT, the International Society of Beverage Technologists, a not for profit scientific society dedicated to education and advancement of knowledge in the beverage industry. Methods and guidelines established by ISBT are widely used as standards and regulations by companies and governments around the world. LH is Executive Director of ISBT. JSW is a consultant and advisor to the food and beverage industry in the area of nutritive sweeteners; clients have an ongoing interest in nutritive sweetener research, development, production, applications, safety, nutrition and education. SF declares no conflict of interest.

\section{ACKNOWLEDGEMENTS}

We gratefully acknowledge expert assistance from the beverage professionals of ISBT.

\section{REFERENCES}

1 Bray GA, Nielsen SJ, Popkin BM. Consumption of high-fructose corn syrup in beverages may play a role in the epidemic of obesity. Am J Clin Nutr 2004; 79: 537-543.

2 Rippe JM, Angelopoulos TJ. Sucrose, high-fructose corn syrup, and fructose, their metabolism and potential health effects: what do we really know? Adv Nutr 2013; 4: $236-245$.

3 Rippe JM, Saltzman E. Sweetened beverages and health: current state of scientific understandings. Adv Nutr 2013; 4: 527-529.

4 Ventura EE, Davis JN, Goran MI. Sugar content of popular sweetened beverages based on objective laboratory analysis: focus on fructose content. Obesity (Silver Spring) 2011; 19: 868-874.

5 White JS. Straight talk about high-fructose corn syrup: what it is and what it ain't. Am J Clin Nutr 2008; 88: 1716S-1721S.

6 Goran Ml, Ulijaszek SJ, Ventura EE. High fructose corn syrup and diabetes prevalence: a global perspective. Glob Public Health 2013; 8: 55-64.

7 ADM Corn Processing. Technical Data Sheet: Typical data information for CornSweet 42, Product code 010042. Archer Daniels Midland Company: Decatur, IL, USA, 2013.

8 ADM Corn Processing. Technical Data Sheet: Typical data information for CornSweet 55, Product code 010055. Archer Daniels Midland Company: Decatur, IL, USA, last accessed 30 October 2013.
9 White JS. Fructose syrup: production, properties, and applications. In: Schenck FW, Hebeda RE (eds) Starch Hydrolysis Products: worldwide technology, production, and application. VCH Publishers, Inc: New York, NY, USA, 1992. pp 177-199.

10 Hanover LM, White JS. Manufacturing, composition, and applications of fructose. Am J Clin Nutr 1993; 58: 724S-732S.

11 White JS. Misconceptions about high-fructose corn syrup: is it uniquely responsible for obesity, reactive dicarbonyl compounds, and advanced glycation endproducts? J Nutr 2009; 139: 1219S-1227S.

12 Buck AW. High fructose corn syrup. In: Nabors LO (ed) Alternative Sweeteners 4th edn. CRC Press: Boca Raton, FL, USA, 2012.

13 Institute of Medicine of the National Academies. Food Chemicals Codex 5th edn. The National Academies Press: Washington, DC, 2003.

14 US Food and Drug Administration. Code of Federal Regulations: High fructose corn syrup. Federal Register, 2009. 21CFR 184.1866: 574.

15 Forshee RA, Storey ML, Allison DB, Glinsmann WH, Hein GL, Lineback DR et al. A critical examination of the evidence relating high fructose corn syrup and weight gain. Crit Rev Food Sci Nutr 2007; 47: 561-582.

16 Fulgoni $V$ 3rd. High-fructose corn syrup: everything you wanted to know, but were afraid to ask. Am J Clin Nutr 2008; 88: 1715 S.

17 Jones JM. Dietary sweeteners containing fructose: overview of a workshop on the state of the science. J Nutr 2009; 139: 1210S-1213S.

18 Murphy SP. The state of the science on dietary sweeteners containing fructose: summary and issues to be resolved. J Nutr 2009; 139: 1269S-1270S.

19 Rippe JM, Kris Etherton PM. Fructose, sucrose, and high fructose corn syrup: modern scientific findings and health implications. Adv Nutr 2012; 3: 739-740.

20 American Medical Association. Report 3 of the Council on Science and Public Health (A-08): The Health Effects of High Fructose Syrup. American Medical Association: Chicago, IL, USA, 2008.

21 Fitch C, Keim KS Academy of N, Dietetics. Position of the Academy of Nutrition and Dietetics: use of nutritive and nonnutritive sweeteners. J Acad Nutr Diet 2012; 112: 739-758.

22 Institute of Medicine. Panel on Macronutrients. Standing Committee on the Scientific Evaluation of Dietary Reference Intakes. Dietary reference intakes for energy, carbohydrate, fiber, fat, fatty acids, cholesterol, protein, and amino acids vol. 1. National Academy Press: Washington, DC, 2005.

23 Johnson RK, Appel LJ, Brands M, Howard BV, Lefevre M, Lustig RH et al. Dietary sugars intake and cardiovascular health: a scientific statement from the American Heart Association. Circulation 2009; 120: 1011-1020.

24 Joint WHO/FAO Expert Consultation. Diet Nutrition and the Prevention of Chronic Diseases. World Health Organization: Geneva, Switzerland, 2003. Report no. 916.

25 Huber $\mathrm{CN}$, Scobell H, Tai H, Fisher EE. Thin-layer chromatography of the maltooligo and megalosaccharides with mixed support and multiple irrigations. Anal Chem 1968; 40: 207-209.

26 Analyses of carbohydrate mixtures by liquid chromatography. American Society of Brewing Chemists. Proceedings 1973.

27 Scobell H, Brobst K, Steele E. Automated liquid chromatographic system for analysis of carbohydrate mixtures [sugar]. Cereal Chem 1977; 54: 905-917.

28 Brobst K, Scobell H. Chromatographic analysis of sugars in cereals and cereal products. Cereal Food World 1981; 26.

29 Brobst K, Scobell H. Modern chromatographic methods for the analysis of carbohydrate mixtures. Starch-Stärke 1982; 34: 117-121.

30 Engel C, Olinger P. High pressure liquid chromatographic determination of saccharides in corn sirups: collaborative study. J Assoc Off Anal Chem 1979; 62.

31 AOAC. 979.23, Saccharides (Major) in Corn Syrup - Liquid Chromatographic Method. In: AOAC Official Methods of Analysis. Association of Official Analytical Chemists: Gaithersburg, MD, USA, 1979.

32 Corn Refiners Association. Method e-61, saccharides (liquid chromatography), tentative standard 9-17-76. In: Standard Analytical Methods of the Member Companies of the Corn Industries Research Foundation. Corn Refiners Association: Washington, DC, 1976.

33 Wartman AM, Hagberg C, Eliason MA. Refractive index-dry substance relations for commercial corn syrups. J Chem Eng Data. 1976; 21: 459-468.

34 Wartman AM, Bridges AJ, Eliason MA. Refractive index-dry substance relationships for commercial high-fructose corn syrups and blends. J Chem Eng Data. 1980; 25: 277-282.

35 Wartman AM, Spawn TD, Eliason MA. Relationship between density, temperature and dry substance of commercial corn syrups, high-fructose corn syrups, and blends with sucrose and invert sugar. J Agric Food Chem 1984; 32: 971-974.

36 International Society of Beverage Technologists. ISBT Method 3.0 - Saccharides in HFCS, Revision 5. In: Quality Guidelines and Analytical Procedures of High Fructose Syrup 42 and 55. International Society of Beverage Technologists: Dallas, TX, USA, 2013.

37 International Society of Beverage Technologists. ISBT Method 3.2 - Saccharides in Soft Drinks. In: Quality Guidelines and Analytical Procedures of High Fructose Syrup 42 and 55. International Society of Beverage Technologists: Dallas, TX, USA, 2013. 
38 United States Pharmacopeial Convention (USP). USP $<921>$ Water Determination. Pharmacopeial Forum 2014; 31: 517.

39 AOAC. Guidelines for Single Laboratory Validation of Chemical Methods for Dietary Supplements and Botanicals. AOAC 2013.

40 Der G, Everitt B A handbook of statistical analyses using SAS, 3rd edn. CRC Press: Boca Raton, FL, USA, 2009.

41 Hsu JC. Multiple Comparisons: Theory and Methods. Chapman \& Hall/CRC Press: Boca Raton, FL, USA, 1996.

42 Hobbs LJ, Krueger D. Response to 'Response to the letter regarding 'Sugar content of popular sweetened beverages'. Obesity (Silver Spring) 2011; 19: 688.

43 Hobbs LJ, Krueger D. Response to 'Sugar content of popular sweetened beverages based on objective laboratory analysis: focus on fructose content'. Obesity (Silver Spring) 2011; 19: 687 author Goran reply 687-8; Hobbs \& Krueger reply to Goran 688

44 White JW. Composition of American honeys. US Department of Agriculture 1962.

45 White, J Doner, LW. Honey composition and properties. Beekeeping in the United States Agriculture Handbook. Agricultural Research Service, United States Department of Agriculture: Washington, DC, USA, 1980. 335, 82-91.

46 Wahjudi PN, Hsieh EA, Pattersn ME, Mao CS, Lee WNP Carbohydrate analysis of high fructose corn syrup (HFCS) containing commercial beverages. FASEB J 2010; meeting abstract supplement: 562.1 .

47 Goran Ml, Ventura EE. Genetic predisposition and increasing dietary fructose exposure: the perfect storm for fatty liver disease in Hispanics in the US Dig Liver Dis 2012; 44: 711-713.

48 Goran MI, Dumke K, Bouret SG, Kayser B, Walker RW, Blumberg B. The obesogenic effect of high fructose exposure during early development. Nat Rev Endocrinol 2013; 9: 494-500.

49 Goran MI. How growing up sweet can turn sour. Pediatr Obes 2013; 8: 237-241.

50 Bray GA, Popkin BM. Calorie-sweetened beverages and fructose: What have we learned 10 years later. Pediatr Obes 2013; 8: 242-248.

51 Melanson KJ, Zukley L, Lowndes J, Nguyen V, Angelopoulos TJ, Rippe JM. Effects of high-fructose corn syrup and sucrose consumption on circulating glucose, insulin, leptin, and ghrelin and on appetite in normal-weight women. Nutrition 2007; 23: 103-112.

52 Soenen S, Westerterp-Plantenga MS. No differences in satiety or energy intake after high-fructose corn syrup, sucrose, or milk preloads. m J Clin Nutr 2007; 86 1586-1594.

53 Melanson KJ, Angelopoulos TJ, Nguyen V, Zukley L, Lowndes J, Rippe JM. High-fructose corn syrup, energy intake, and appetite regulation. Am J Clin Nutr 2008; 88: 1738S-1744S.
54 Stanhope KL, Griffen SC, Bair BR, Swarbrick MM, Keim NL, Havel PJ. Twentyfour-hour endocrine and metabolic profiles following consumption of high-fructose corn syrup-, sucrose-, fructose-, and glucose-sweetened beverages with meals. Am J Clin Nutr 2008; 87: 1194-1203.

55 Angelopoulos TJ, Lowndes J, Zukley L, Melanson KJ, Nguyen V, Huffman A et al. The effect of high-fructose corn syrup consumption on triglycerides and uric acid. J Nutr 2009; 139: 1242S-1245S.

56 Lowndes J, Kawiecki D, Pardo S, Nguyen V, Melanson KJ, Yu Z et al. The effects of four hypocaloric diets containing different levels of sucrose or high fructose corn syrup on weight loss and related parameters. Nutr $J$ 2012; 11: 55.

57 Bravo S, Lowndes J, Sinnett S, Yu Z, Rippe J. Consumption of sucrose and high-fructose corn syrup does not increase liver fat or ectopic fat deposition in muscles. Appl Physiol Nutr Metab 2013; 38: 681-688.

$58 \mathrm{Yu} \mathrm{Z}$, Lowndes J, Rippe J. High-fructose corn syrup and sucrose have equivalent effects on energy-regulating hormones at normal human consumption levels. Nutr Res 2013; 33: 1043-1052.

59 Bray GA. Energy and fructose from beverages sweetened with sugar or high-fructose corn syrup pose a health risk for some people. Adv Nutr 2013; 4 220-225.

60 Lustig RH. Fructose: it's 'alcohol without the buzz'. Adv Nutr 2013; 4: 226-235.

61 White JS. Challenging the fructose hypothesis: new perspectives on fructose consumption and metabolism. Adv Nutr 2013; 4: 246-256.

62 Klurfeld DM, Foreyt J, Angelopoulos TJ, Rippe JM. Lack of evidence for high fructose corn syrup as the cause of the obesity epidemic. Int J Obes (Lond) 2012; 37: 771-773.

63 Johnston RD, Stephenson MC, Crossland H, Cordon SM, Palcidi E, Cox EF et al. No difference between high-fructose and high-glucose diets on liver triacylglycerol or biochemistry in healthy overweight men. Gastroenterology 2013; 145: 1016-1025 e2.

(1) This work is licensed under a Creative Commons Attributioncc. NonCommercial-NoDerivs 3.0 Unported License. The images or other third party material in this article are included in the article's Creative Commons license, unless indicated otherwise in the credit line; if the material is not included under the Creative Commons license, users will need to obtain permission from the license holder to reproduce the material. To view a copy of this license, visit http://creativecommons.org/licenses/by-nc-nd/3.0/ 